\title{
Pengujian Pengaruh Ketinggian Weir pada Koefisien Discharge dari Weirmeter Sharp-Crested V-Notch 90 ${ }^{\circ}$
}

\author{
Komarudin ${ }^{1}$, Suprijatmono ${ }^{2}$, Gennady Chitra Pati ${ }^{3}$ \\ Program Studi S1 Teknik Mesin, Institut Sains dan Teknologi Nasional, Jakarta Selatan ${ }^{1} 23$ \\ email $^{1}$ : komarudin.mt@gmail.com
}

\begin{abstract}
Weirmeter is a discharge gauge on an open-channel flow that is usually applied to dams and rivers. In each weirmeter there is a discharge coefficient $(C d)$, which is the coefficient multiplied by the theoretical discharge to obtain the actual discharge because the pressure difference and flow velocity are neglected. The Cd is directly proportional to the discharge. The actual debit measurement results do not approximate the result (the multiplication of the theoretical debit with $C d$ ). This difference may be due to unequal $C d$ values for each weir dimension, one of which is the weir height $(P)$. Therefore it is necessary to test the weirmeter with $P$ varies in order to know the pattern and the value of $C d$. The tested weirmeter is sharp-crested v-notch $90^{\circ}$ with a length of $200 \mathrm{~cm}$ and a width of $35.5 \mathrm{~cm}$. P used is $20.3 \mathrm{~cm} ; 21.3 \mathrm{~cm}$; and $22.3 \mathrm{~cm}$. From the test, the Cd value is inversely proportional to $P$ although some of these test results are far from the theory because it requires a 90\% confidence interval on the Student distribution ( $t$ distribution). The value of $C d$ in weirmeter used is 0.6996 for $P 20.3 \mathrm{~cm}$; 0.6657 for $P 21.3 \mathrm{~cm}$; and 0.5781 for $P 22.3 \mathrm{~cm}$.
\end{abstract}

Keywords: weir height, weirmeter sharp-crested v-notch $90^{\circ}$, discharge coefficient, openchannel flow

\section{PENDAHULUAN}

Weirmeter adalah alat ukur debit fluida pada sistem terbuka yang biasanya diaplikasikan pada bendungan dan sungai. Alat ukur ini bisa digunakan pada skala yang besar. Weirmeter sangat sederhana dan tidak membutuhkan biaya yang besar dalam pembuatannya.

Pentingnya weirmeter adalah ketika instalasi alat ukur lain tidak mampu dilakukan pada sistem terbuka dengan skala yang besar weirmeter dapat melakukannya dengan dimensi weirmeter yang disesuaikan. Karena kemampuannya dalam melakukan pengukuran pada skala fluida besar dan ongkos produksi yang rendah weirmeter berperan penting dalam analisis dimensional.

Pada Laboratorium Mesin Fluida Institut Teknologi Bandung (LMF ITB) terdapat weirmeter sharp-crested v-notch $90^{\circ}$ untuk keperluan pengujian. Pada setiap weirmeter terdapat koefisien discharge $(\mathrm{Cd})$, yaitu koefisien yang dikalikan dengan debit teoritik untuk mendapatkan debit aktual karena diabaikannya perbedaan tekanan dan kecepatan aliran untuk menghitung debit teoritik. Namun, hasil pengukuran debit aktual tidak mendekati hasil hitungnya (perkalian debit teoritik dengan $\mathrm{Cd}$ ).
Perbedaan dapat disebabkan oleh nilai Cd yang tidak sama untuk setiap dimensi weir, salah satunya ketinggian weir, meski dimensi weirmeter yang dipakai adalah tetap. Maka dari itu perlu dilakukan pengujian pada weirmeter dengan ketinggian weir yang bervariasi. Ketinggian weir diketahui memiliki hubungan yang berbanding terbalik dengan koefisien discharge pada weirmeter yang takiknya berbentuk rectangular.

Dari latar belakang diatas tujuan yang hendak dicapai penelitian adalah mengetahui nilai $\mathrm{Cd}$ pada weirmeter untuk masing-masing ketinggian weir, pola $\mathrm{Cd}$ pada weirmeter jika ketinggian weir divariasikan, membandingkan nilai dan pola $\mathrm{Cd}$ pada variasi ketinggian weir dengan literatur.

\section{TINJAUAN PUSTAKA}

\section{Pengertian Weirmeter}

Weirmeter adalah struktur untuk aliran air yang dibuat secara terbuka dalam udara yang digunakan untuk mengukur laju volume dari air. Weirmeter dirancang untuk kebutuhan aliran besar yang bersifat terbuka. Perhitungan debit pada weirmeter dilakukan dengan pendekatan ketinggian air yang akan melewati weir. Ketinggian air sering 
disebut dengan head. Jaraknya adalah antara dasar takikan weir dengan ketinggian air pada saat melewati weir. Kenyataannya ketinggian permukaan air yang jauh dengan weir dan ketinggian permukaan air yang akan melewati weir adalah berbeda karena perubahan kecepatan air.

Weirmeter harus terlebih dahulu dikalibrasi sebelum melakukan pengukuran. Kalibrasi dilakukan dengan menghitung nilai dari koefisien discharge $(\mathrm{Cd})$. $\mathrm{Cd}$ adalah nilai koefisien yang berbeda untuk berbagai jenis weir. Koefisien discharge dibutuhkan untuk membuat lebih teliti nilai dari debit air yang diukur.

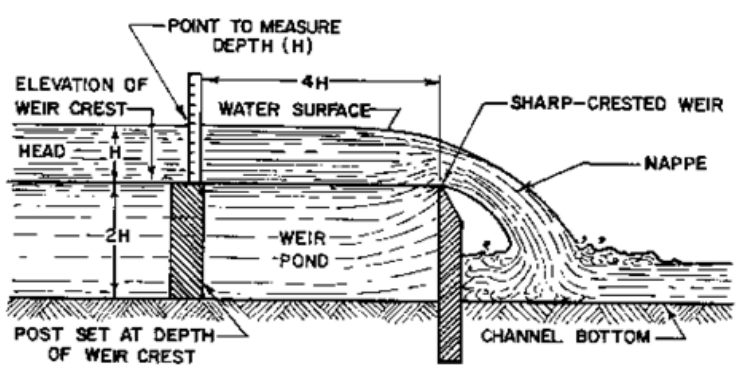

Gambar 1. Skema weirmeter

\section{Persamaan Debit Pada Weirmeter Sharp- Crested V-notch}

Dalam penurunan persamaan debit air pada weirmeter segitiga digunakan beberapa asumsi agar didapatkan persamaan yang tidak terlalu rumit.

1. Distribusi kecepatan sepanjang weirmeter seragam

2. Tekanan atmosfer yang bekerja pada nappe

3. Analisis volume atur

4. Pengaruh tegangan permukaan, timbulnya vortex, dan viskositas diabaikan

5. Asumsi pada Persamaan Bernoulli

Pergerakan partikel fluida dari suatu titik ke titik lain dapat diperkirakan menggunakan persamaan Bernoulli.

$$
\mathrm{Z}_{1}+\frac{\mathrm{v}_{1}^{\mathrm{z}}}{2 \mathrm{~g}}+\frac{\mathbf{p}_{1}}{\gamma}=\mathrm{Z}_{2}+\frac{\mathrm{v}_{2}^{\mathrm{z}}}{2_{\mathrm{g}}}+\frac{\mathrm{p}_{\mathrm{z}}}{\gamma}
$$

$\mathrm{Z}=$ ketinggian dari acuan

$\mathrm{P}=$ tekanan pada titik tertentu

$\gamma=$ berat jenis fluida

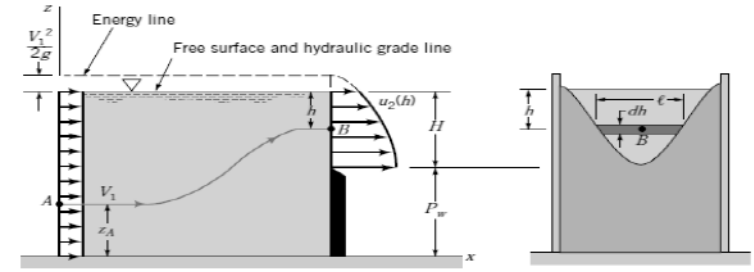

Gambar 2. Analisis volume atur saluran terbuka weirmeter

Karena tekanan sepanjang weirmeter diasumsikan seragam dan tinggi acuan adalah ujung takikan dari weirmeter maka persamaan Bernoulli dapat disederhanakan menjadi:

$$
\begin{aligned}
& \mathrm{H}+\frac{\mathrm{v}_{1}^{2}}{2 \mathrm{~g}}=(\mathrm{H}-\mathrm{h})+\frac{\mathrm{v}_{2}^{\mathrm{z}}}{2 \mathrm{~g}} \\
& \mathrm{~V}_{2}=\sqrt{2 \mathrm{~g}\left(\mathrm{~h}+\frac{\mathrm{v}_{1}^{\mathrm{z}}}{2 \mathrm{~g}}\right)}
\end{aligned}
$$

$\mathrm{H}=$ jarak takik weir dengan permukaan air di hulu weirmeter

$\mathrm{h}=$ jarak permukaan air titik 2 dengan weir crest

Persamaan debit (Q) pada weirmeter adalah sebagai berikut:

$$
\mathrm{Q}=\int_{0}^{\mathrm{H}}\left(\mathrm{v}_{2} \mathrm{w}\right) \mathrm{dh}
$$

$\mathrm{w}=$ lebar $v$ - notch

Karena takikan berbentuk segitiga maka lebar merupakan fungsi ketinggian sehingga diperlukan diferensiasi persamaan.

$$
\begin{aligned}
& \tan \frac{\theta}{2}=\frac{0,5 \mathrm{w}}{\mathrm{H}-\mathrm{h}} \\
& \mathrm{w}=2(\mathrm{H}-\mathrm{h}) \tan \frac{\theta}{2}
\end{aligned}
$$

Kemudian substitusi persamaan 10 dan 7 ke dalam persamaan 8 ,

$$
Q=\int_{0}^{H} \sqrt{2 g\left(h+\frac{w_{1}^{2}}{2 g}\right)}\left(2 \tan \frac{\theta}{2}\right)(H-h) d h
$$

Nilai $\mathrm{v}_{1}$ sangatlah kecil dibandingkan dengan nilai dari $h_{x}$ sehingga dapat diabaikan,

$$
\mathrm{Q}=\int_{0}^{\mathrm{H}} \sqrt{2 \mathrm{gh}}\left(2 \tan \frac{\theta}{2}\right)(\mathrm{H}-\mathrm{h}) \mathrm{dh}
$$

Persamaan 8 kemudian diintegralkan menjadi persamaan baru

$$
\mathrm{Q}=\frac{\mathrm{s}}{15} \sqrt{2 \mathrm{~g}} \tan \left(\frac{\theta}{2}\right) \mathrm{H}^{2,5}
$$




\section{Koefisien Discharge}

Hasil debit teoritik (persamaan 2.16) dari perhitungan dibandingkan dengan debit sebenarnya adalah berbeda dikarenakan sejumlah asumsi yang digunakan. Karena itu dibutuhkan sebuah faktor koreksi agar nilai dari debit teoritik dari sesuai dengan debit sesungguhnya.

Koefisien discharge (Cd) digunakan sebagai konstanta pengali dari debit teoritik agar debit teoritik teliti terhadap debit sesungguhnya.

$$
\mathrm{Cd}=\frac{\mathrm{Q}}{\mathrm{Q}_{\text {teoritik }}}
$$

Sehingga jika persamaan 17 digabungkan dengan persamaan 16 ,

$$
\begin{gathered}
\mathrm{K}=\frac{8}{15} \sqrt{2 \mathrm{~g}} \tan \left(\frac{\theta}{2}\right) \\
\mathrm{Q}=\mathrm{Cd} \mathrm{K} \mathrm{H} \mathrm{H}^{2,5}
\end{gathered}
$$

$$
\mathrm{H}=\text { jarak dari notch ke permukaan fluida }
$$

\section{Cd Pada Weirmeter Sharp-Crested V-Notch $90^{\circ}$}

Terdapat beberapa nilai koefisien discharge (Cd) pada weirmeter sharp-crested v-notch $90^{\circ}$. Yang paling pertama berasal dari James Thomson pada tahun 1861. Dari percobaan-percobaan yang dilakukannya, Thomson menyimpulkan bahwa $\mathrm{Cd}$ pada weirmeter sharp-crested v-notch $90^{\circ}$ adalah 0,593 .

$$
\mathrm{Cd}=0,593
$$

Pada tahun 1910, James Barr dan T.P. Strickland menyimpulkan nilai Cd pada weirmeter tipe $v$ notch $90^{\circ}$ adalah:

$$
\mathrm{Cd}=0,566+\frac{0,0157}{\sqrt{\mathrm{H}}}
$$

$\mathrm{H}=$ jarak dari notch ke permukaan fluida (dalam satuan feet)

V.M. Cone pada tahun 1916 juga memiliki formula tersendiri untuk mencari Cd pada weirmeter sharp-crested $v$-notch $90^{\circ}$, yaitu:

$$
\mathrm{Cd}=\frac{0,58184}{\mathrm{H}^{0,0195}}
$$

Pada tahun 1932, F.W. Greve menemukan pola untuk menemukan $\mathrm{Cd}$ yang tepat untuk weirmeter yang sama sebagai berikut:

$$
\mathrm{Cd}=\frac{0,585}{\mathrm{H}^{0,085}}
$$

Berikutnya Arno T. Lenz pada tahun 1943 merumuskan $\mathrm{Cd}$ pada weirmeter sharp-crested $v$ notch $90^{\circ}$ sebagai berikut:

$$
\mathrm{Cd}=0,56+\frac{0,0159}{\mathrm{H}^{0,588}}
$$

Untuk Cd pada weirmeter sharp-crested vnotch $90^{\circ}$, H.W. King pada tahun 1954 menyimpulkan persamaan 18 di bawah ini:

$$
\mathrm{Cd}=\frac{0,589}{\mathrm{H}^{0,08}}
$$

Numachi, Kurokawa, dan Hutizawa pada tahun 1940 merumuskan Cd pada weirmeter sharp-crested v-notch $90^{\circ}$ tidak hanya dengan memasukkan $\mathrm{H}$, tetapi juga dengan memasukkan ketinggian weir $(\mathrm{P}$, jarak dari notch ke dasar weirmeter, dalam satuan feet) dan lebar weir (B, dalam satuan feet), yakni:

$$
\begin{aligned}
& \mathrm{Cd}=0,574+\frac{0,0055}{\mathrm{H}}+(0,055+ \\
& \left.\frac{0,278}{0,886+\mathrm{P}}\right)\left[\frac{\mathrm{H}}{\mathrm{B}}-\left(0,1-\frac{0,0098}{0,079+\mathrm{P}}\right)\right]^{2}
\end{aligned}
$$

Untuk memberikan gambaran secara jelas tentang perbedaan dari persamaan 13 sampai dengan 19 di atas, maka dapat dibuat diagram Cd terhadap $\mathrm{H}$ dan diagram $\mathrm{Cd}$ terhadap $\mathrm{H} / \mathrm{P}$ yang terdapat pada beberapa gambar berikut (Cd dicantumkan sebagai C di dalam gambar), yaitu Gambar 4, 5, dan 6.

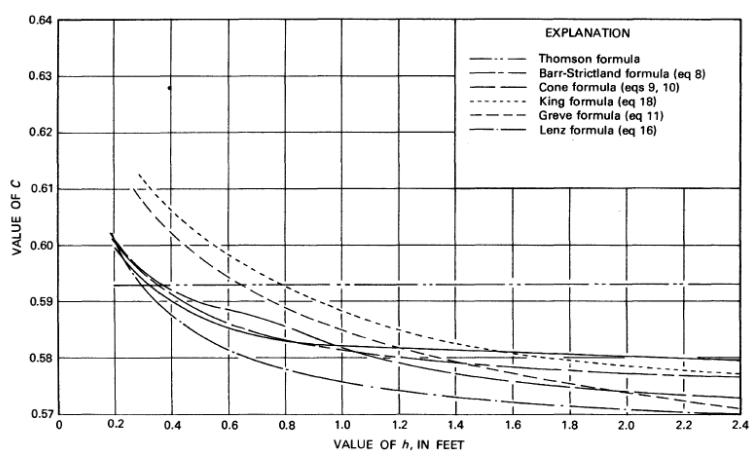

Gambar 3. Diagram Cd terhadap H

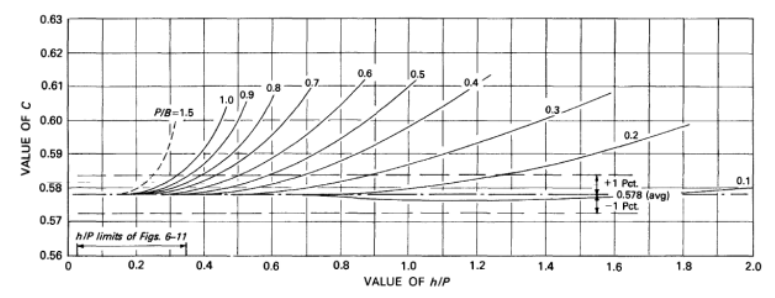

Gambar 4. Diagram Cd terhadap H/P yang disertai kurva-kurva P/B 


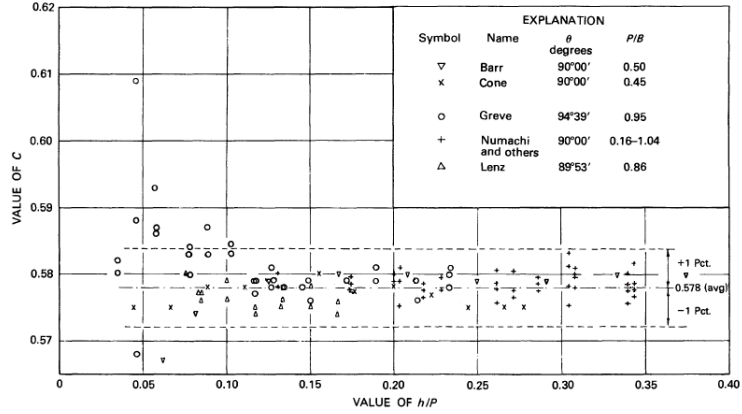

Gambar 5. Diagram Cd terhadap H/P dalam rentang tertentu

\section{PROSEDUR PENGAMBILAN DATA}

Pengambilan data dilakukan melalui pengujian dalam besar debit air yang berbeda-beda pada masing-masing ketinggian weir sharp-crested $v$ notch $90^{\circ}$. Variasi debit air adalah $1 ; 1,5 ; 2 ; 2,5 ; 3$; 3,5 ; 4; dan 4,5 putaran katup. Variasi ketinggian weir (P) adalah 20,3 cm; 21,3 cm; dan $22,3 \mathrm{~cm}$. Weirmeter yang digunakan memiliki panjang 2 meter dan lebar 0,355 meter. Cara mengukur debit air adalah menggunakan wadah berkapasitas 20 liter dan stopwatch, yaitu dengan mendapatkan lama waktu supaya wadah penuh terisi air. Untuk mengukur $\mathrm{H}$ (jarak dari notch ke permukaan air) digunakan mistar. Pengukuran debit air dan $\mathrm{H}$ dilakukan saat kondisi tunak. Adapun pipa, pompa, dan wadah yang digunakan dalam setiap pengujian memiliki spesifikasi yang selalu sama.

\section{Alat-Alat yang Digunakan}

Adapun alat-alat yang digunakan dalam pengujian adalah:

1. weirmeter dengan panjang 2 meter dan lebar 0,355 meter

2. weir sharp-crested v-notch $90^{\circ}$ dengan variasi ketinggian $(\mathrm{P})$ pada $20,3 \mathrm{~cm}, 21,3 \mathrm{~cm}$, dan 22,3 $\mathrm{cm}$

3. wadah air yang telah diketahui volumenya (20 liter)

4. stopwatch, mistar, dan pompa air

katup pada pipa untuk memberi variasi debit air dengan delapan variasi dari 1 sampai dengan 4,5 putaran katup

\section{HASIL PENGAMBILAN DATA}

Pada setiap ketinggian weir, yaitu $20,3 \mathrm{~cm}, 21,3$ $\mathrm{cm}$, dan $22,3 \mathrm{~cm}$, pengambilan data dilakukan pada 8 variasi debit dengan selisih tiap variasi debit sebesar 0,5 putaran katup. Debit terendah didapat dengan membuka katup sebesar 1 putaran, sedangkan debit terbesar didapat dengan membuka katup 4,5 putaran. Nilai $\mathrm{K}$ yang didapat dari persamaan 11 adalah sebesar $7,459 \mathrm{dm}^{0,5} / \mathrm{s}$ atau $4,278 \mathrm{ft}^{0,5} / \mathrm{s}$. Besar nilai $\mathrm{K}$ selalu sama pada setiap variasi debit dan ketinggian weir.
Tabel 1. Hasil Pengambilan Data

\begin{tabular}{|c|c|c|c|c|c|c|}
\hline \multirow{2}{*}{$\begin{array}{l}\text { Puta- } \\
\text { ran } \\
\text { katup }\end{array}$} & \multicolumn{2}{|c|}{$P=20,3 \mathrm{~cm}$} & \multicolumn{2}{|c|}{$P=21,3 \mathrm{~cm}$} & \multicolumn{2}{|c|}{$P=22,3 \mathrm{~cm}$} \\
\hline & $\begin{array}{c}\mathbf{Q} \\
(\mathbf{l} / \mathbf{s})\end{array}$ & $\begin{array}{c}\mathbf{H} \\
(\mathbf{d m})\end{array}$ & $\begin{array}{c}\mathbf{Q} \\
(\mathbf{l} / \mathbf{s})\end{array}$ & $\begin{array}{c}\mathbf{H} \\
(\mathbf{d m})\end{array}$ & $\begin{array}{c}\mathbf{Q} \\
(\mathbf{l} / \mathbf{s})\end{array}$ & $\begin{array}{c}\mathbf{H} \\
(\mathbf{d m})\end{array}$ \\
\hline 1 & 1,052 & 0,6 & 0,65 & 0,44 & 0,60 & 0,44 \\
\hline 1,5 & 2,243 & 0,71 & 1,49 & 0,61 & 1,63 & 0,6 \\
\hline 2 & 3,337 & 0,84 & 2,64 & 0,77 & 2,74 & 0,77 \\
\hline 2,5 & 3,914 & 0,87 & 3,44 & 0,85 & 3,64 & 0,85 \\
\hline 3 & 4,252 & 0,9 & 4,34 & 0,92 & 4,16 & 0,93 \\
\hline 3,5 & 4,451 & 0,93 & 4,63 & 0,94 & 4,17 & 0,98 \\
\hline 4 & 4,539 & 0,96 & 5,11 & 1,01 & 4,47 & 1,02 \\
\hline 4,5 & 4,691 & 1 & 5,29 & 1,04 & 5,31 & 1,04 \\
\hline
\end{tabular}

\section{PENGOLAHAN DATA HASIL HITUNG}

Berdasar Tabel 1 dapat diagram Q/K terhadap $\mathrm{H}^{2,5}$ dan diagram $\mathrm{Cd}$ terhadap $\mathrm{H} / \mathrm{P}$ pada persamaan 14 sampai dengan 19 dengan $\mathrm{Q}$ atau $\mathrm{H}$ dari Tabel 1 sebagai acuan. Dari diagram Q/K terhadap $\mathrm{H}^{2,5}$ dapat ditentukan $\mathrm{Cd}$ rata-rata $\left(\mathrm{Cd}_{\text {avg }}\right)$, yaitu gradien garis lurus pada diagram. Diagram $\mathrm{Cd}$ terhadap $\mathrm{H} / \mathrm{P}$ digunakan karena sesuai dengan Gambar 4 dan 5.

\section{PENGOLAHAN DATA HASIL UKUR}

Jika Tabel 1 diolah, maka diagram-diagram yang dihasilkan adalah:

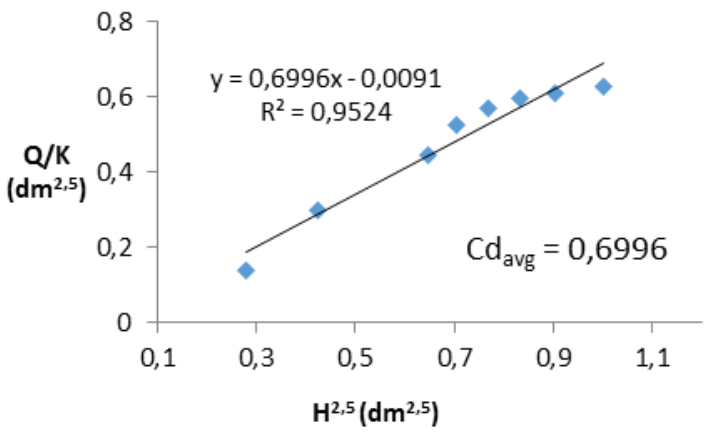

Gambar 6: Diagram Q/K terhadap $\mathrm{H}^{2,5}$ pada $\mathrm{P}$ $20,3 \mathrm{~cm}$

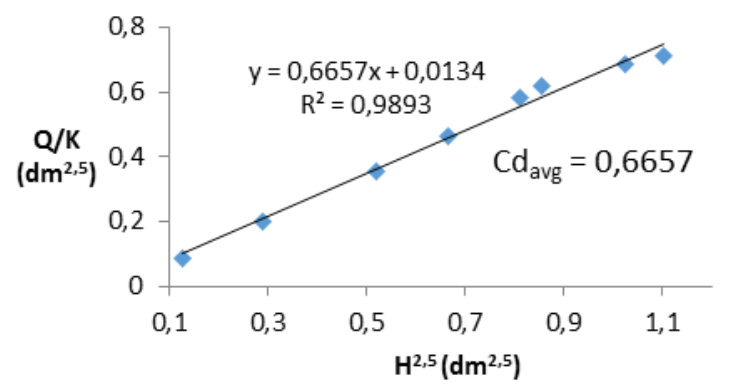

Gambar 7: Diagram Q/K terhadap $\mathrm{H}^{2,5}$ pada $\mathrm{P}$ $21,3 \mathrm{~cm}$ 


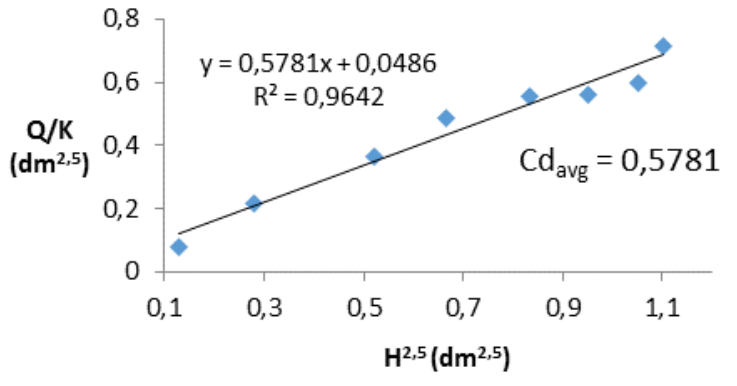

Gambar 8: Diagram Q/K terhadap $\mathrm{H}^{2,5}$ pada $\mathrm{P} 22,3 \mathrm{~cm}$

\section{ANALISIS HASIL}

Perbedaan persamaan 14 sampai dengan 19 dapat dilihat melalui Tabel 2 dan Gambar 4 dan 5 berikut yang merupakan rangkuman pengolahan data hasil hitung:

Tabel 2. Hasil hitung $\mathrm{Cd}_{\text {avg }}$

\begin{tabular}{|c|c|c|c|c|}
\hline $\begin{array}{l}\text { Persa- } \\
\text { maan }\end{array}$ & $\begin{array}{c}\text { sebagai } \\
\text { acuan }\end{array}$ & $\begin{array}{c}\text { besar } \\
\mathbf{P} \\
(\mathbf{c m})\end{array}$ & \multicolumn{2}{|c|}{ Cd $_{\text {avg }}$} \\
\hline \multirow{6}{*}{14} & \multirow{3}{*}{$\mathrm{H}$} & 20,3 & 0,5901 & \multirow{3}{*}{0,5905} \\
\hline & & 21,3 & 0,5906 & \\
\hline & & 22,3 & 0,5905 & \\
\hline & \multirow{3}{*}{ Q } & 20,3 & 0,58997 & \multirow{3}{*}{0,5901} \\
\hline & & 21,3 & 0,59000 & \\
\hline & & 22,3 & 0,5903 & \\
\hline \multirow{6}{*}{15} & \multirow{3}{*}{$\mathrm{H}$} & 20,3 & 0,5921 & \multirow{3}{*}{0,5924} \\
\hline & & 21,3 & 0,5925 & \\
\hline & & 22,3 & 0,5924 & \\
\hline & \multirow{3}{*}{ Q } & 20,3 & 0,59198 & \multirow{3}{*}{0,5921} \\
\hline & & 21,3 & 0,59196 & \\
\hline & & 22,3 & 0,5922 & \\
\hline \multirow{6}{*}{16} & \multirow{3}{*}{$\mathrm{H}$} & 20,3 & 0,6010 & \multirow{3}{*}{0,6014} \\
\hline & & 21,3 & 0,6015 & \\
\hline & & 22,3 & 0,6014 & \\
\hline & \multirow{3}{*}{ Q } & 20,3 & 0,60087 & \multirow{3}{*}{0,6010} \\
\hline & & 21,3 & 0,60085 & \\
\hline & & 22,3 & 0,6013 & \\
\hline \multirow{6}{*}{17} & \multirow{3}{*}{$\mathrm{H}$} & 20,3 & 0,5862 & \multirow{3}{*}{0,5866} \\
\hline & & 21,3 & 0,5868 & \\
\hline & & 22,3 & 0,5867 & \\
\hline & \multirow{3}{*}{ Q } & 20,3 & 0,58600 & \multirow{3}{*}{0,5862} \\
\hline & & 21,3 & 0,58604 & \\
\hline & & 22,3 & 0,5864 & \\
\hline \multirow{6}{*}{18} & \multirow{3}{*}{$\mathrm{H}$} & 20,3 & 0,6051 & \multirow{3}{*}{0,6055} \\
\hline & & 21,3 & 0,6057 & \\
\hline & & 22,3 & 0,6056 & \\
\hline & \multirow{3}{*}{ Q } & 20,3 & 0,60503 & \multirow{3}{*}{0,6052} \\
\hline & & 21,3 & 0,60501 & \\
\hline & & 22,3 & 0,6054 & \\
\hline \multirow{6}{*}{19} & \multirow{3}{*}{$\mathrm{H}$} & 20,3 & 0,59770 & \\
\hline & & 21,3 & 0,59771 & 0,5976 \\
\hline & & 22,3 & 0,5976 & \\
\hline & & 20,3 & 0,5982 & \\
\hline & Q & 21,3 & 0,5985 & 0,5982 \\
\hline & & 22,3 & 0,5979 & \\
\hline
\end{tabular}

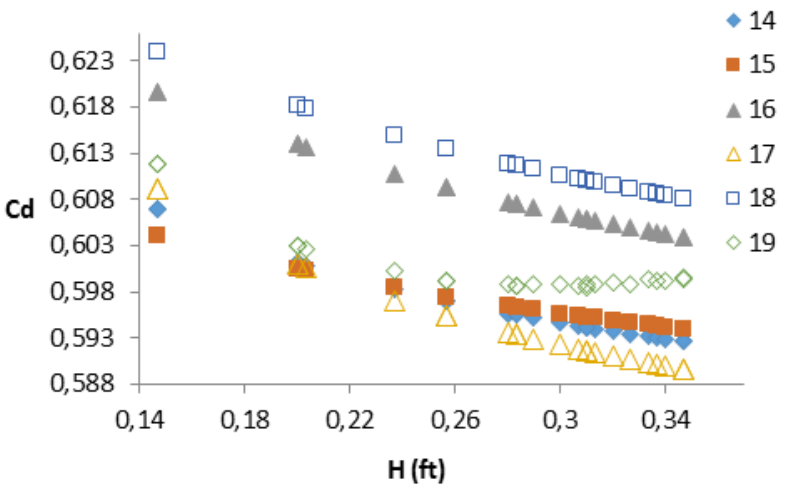

Gambar 9. Diagram Cd terhadap H jika H sebagai acuan

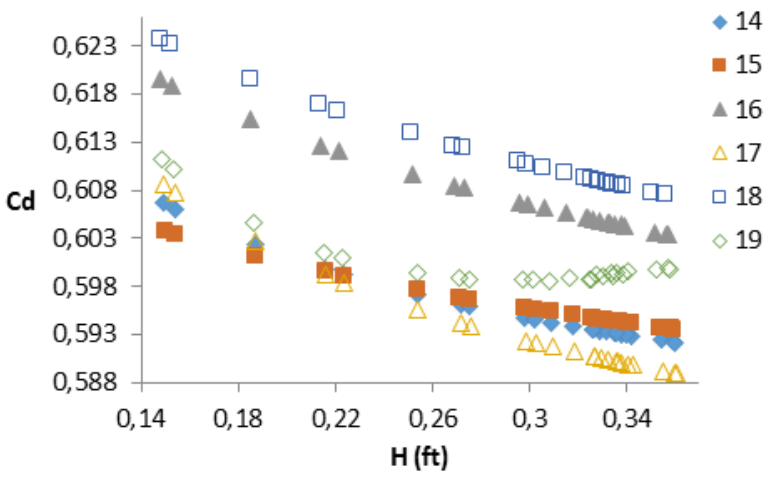

Gambar 10. Diagram Cd terhadap H jika Q sebagai acuan

Melalui Tabel 2 dan Gambar 4 dan 5, maka dapat ditentukan urutan persamaan 18 sampai dengan 23 berdasar besar $\mathrm{Cd}$. Urutan terjadi karena besar konstanta pada masing-masing persamaan. Tidak seperti pada persamaan 14 sampai dengan 18, pada persamaan 19 nilai $\mathrm{H}$ tidak hanya berbanding terbalik dengan $\mathrm{Cd}$ seperti persamaan lain, melainkan juga berbanding lurus. Dengan nilai $\mathrm{Cd}$ yang lebih besar, maka $Q$ yang dihasilkan juga lebih besar karena $\mathrm{Cd}$ dengan $\mathrm{Q}$ berbanding lurus.

Dengan Tabel 2 juga didapat nilai $\mathrm{Cd}_{\text {avg }}$ yang lebih besar jika $\mathrm{H}$ digunakan sebagai acuan, kecuali pada persamaan 19 yang mana $\mathrm{Cd}_{\text {avg }}$ lebih besar jika Q digunakan sebagai acuan. Sayangnya membandingkan $\mathrm{H}$ hasil ukur (H merupakan sebagai acuan) dengan $\mathrm{H}$ hasil hitung (Q merupakan sebagai acuan) dan membandingkan $Q$ hasil ukur (Q merupakan sebagai acuan) dengan $\mathrm{Q}$ hasil hitung $(\mathrm{H}$ merupakan sebagai acuan) pada putaran katup yang sama tidak dapat menjelaskan, karena nilai $\mathrm{H}$ dan $\mathrm{Q}$ jika $\mathrm{H}$ sebagai acuan lebih kecil dari nilai $\mathrm{H}$ dan $\mathrm{Q}$ jika Q sebagai acuan, meski hanya tidak terjadi pada putaran katup sebesar satu dan P sebesar $20,3 \mathrm{~cm}$.

Berbedanya bentuk persamaan 19 dapat menjadi alasan mengapa hanya pada persamaan 19 nilai $\mathrm{Cd}_{\text {avg }}$ dengan $\mathrm{Q}$ sebagai acuan dapat lebih besar dari H sebagai acuan. Melalui Gambar 9 dan 10, Cd 
dari penghitungan persamaan 19 terlihat mengecil lalu membesar, sedangkan $\mathrm{Cd}$ pada penghitungan persamaan 14 sampai dengan 19 akan mengecil seiring membesarnya $\mathrm{H}$. Baik Gambar 10 maupun 9 telah memiliki kesesuaian dengan Gambar 3.

Bagaimana dengan pengaruh $\mathrm{P}$ pada $\mathrm{Cd}$ hasil hitung? Gambar 4 dan 5 yang merupakan diagram $\mathrm{Cd}$ terhadap $\mathrm{H} / \mathrm{P}$ dapat menjadi petunjuk. Jika diagram $\mathrm{Cd}$ terhadap $\mathrm{H} / \mathrm{P}$ dibuat dengan pengolahan data hasil hitung maka didapat bahwa semakin besar $\mathrm{P}$ akan memperkecil nilai $\mathrm{Cd}$, tetapi penyataan barusan tidak dapat dibenarkan karena absis diagram tersebut adalah $\mathrm{H} / \mathrm{P}$ yang artinya jika nilai $\mathrm{H}$ tetap dan nilai $\mathrm{P}$ berubah-ubah, maka $\mathrm{P}$ yang lebih besar memang akan berada di sebelah kiri $\mathrm{P}$ yang lebih kecil. Namun, diagram $\mathrm{H}$ terhadap $\mathrm{Cd}$ pada persamaan 19 pada Gambar 11 dan 12 di bawah ini dapat memperkirakan hubungan $\mathrm{P}$ dengan $\mathrm{Cd}$ :

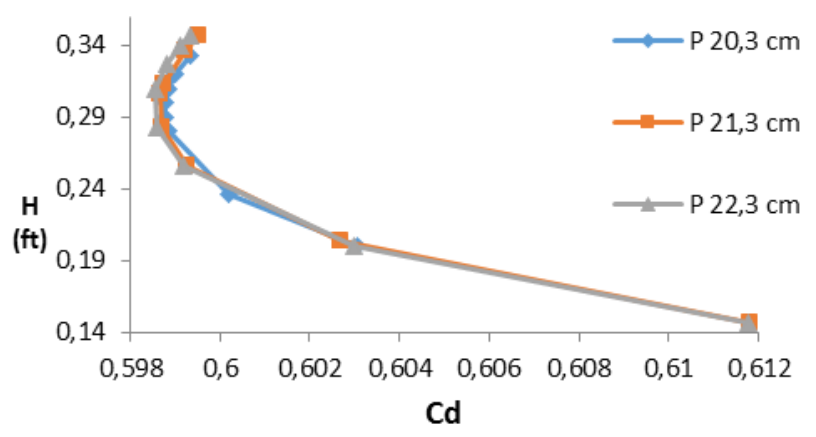

Gambar 11. Diagram H terhadap Cd pada persamaan 19 dengan $\mathrm{H}$ sebagai acuan

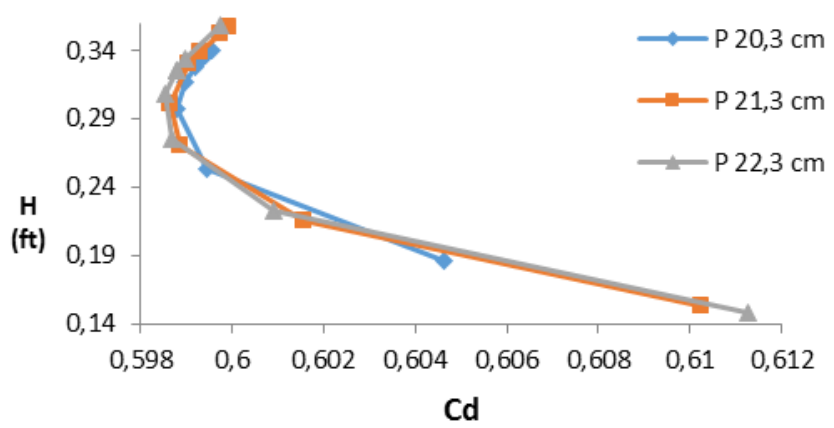

Gambar 12. Diagram H terhadap Cd pada persamaan 19 dengan $Q$ sebagai acuan

Melalui Gambar 11 dan 12 sudah mulai terlihat jika semakin besar nilai $\mathrm{P}$ akan memperkecil nilai $\mathrm{Cd}$ yang baru bisa terlihat jika $\mathrm{H}$ lebih besar dari 0,3. Karena $\mathrm{Cd}$ berbanding lurus dengan $\mathrm{Q}$ dan $\mathrm{Cd}$ berbamding terbalik dengan $\mathrm{P}$, maka $\mathrm{P}$ berbanding terbalik dengan $\mathrm{Q}$.

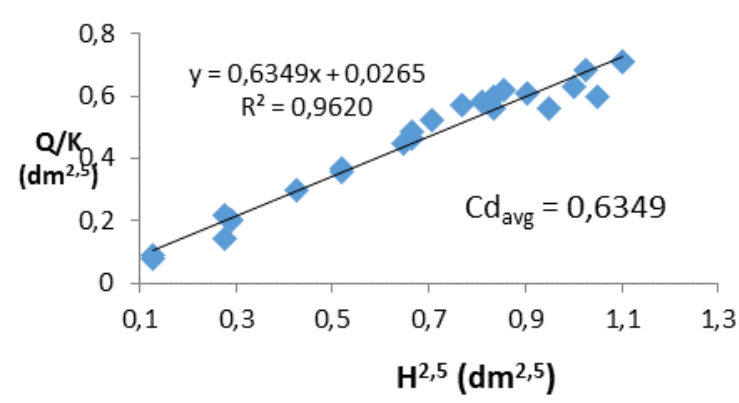

Gambar 13. Diagram Q/K terhadap $\mathrm{H}^{2,5}$ hasil pengukuran

Dari Gambar 14 menunjukkan bahwa $\mathrm{Cd}_{\text {avg }}$ hasil uji berada jauh dari $\mathrm{Cd}_{\text {avg }}$ hasil hitung, yang berarti $\mathrm{H}$ hasil ukur lebih kecil dan $\mathrm{Q}$ hasil ukur lebih besar dari seharusnya. Nilai $H$ hasil ukur yang lebih kecil dari seharusnya terjadi karena kesalahan paralaks, sementara nilai $\mathrm{Q}$ hasil ukur yang lebih besar dari seharusnya dapat terjadi karena wadah penampung yang tergolong kecil jika Q cukup besar. $\mathrm{H}$ hasil ukur yang lebih kecil dan Q hasil ukur yang lebih besar dari seharusnya terkait dengan $\mathrm{Cd}_{\mathrm{avg}}$ hasil hitung yang lebih besar nilainya jika $\mathrm{H}$ sebagai acuan dibanding $\mathrm{Q}$ sebagai acuan.

Untuk melengkapi perbedaan hasil ukur dengan hasil hitung dapat melalui distribusi Student (atau disebut juga distribusi t) dapat dilihat pada Tabel 3 berikut:

Tabel 3. Perbandingan $\mathrm{Cd}_{\text {avg }}$ hasil ukur dengan hasil hitung

\begin{tabular}{|c|c|c|c|}
\hline \multirow{2}{*}{$\mathbf{P}$} & \multirow{2}{*}{$\begin{array}{l}\text { Cdavg } \\
\text { hasil } \\
\text { ukur }\end{array}$} & \multicolumn{2}{|c|}{$\begin{array}{c}\text { interval } \\
\text { kepercayaan }\end{array}$} \\
\hline & & $90 \%$ & $20 \%$ \\
\hline $20,3 \mathrm{~cm}$ & 0,6996 & $\begin{array}{c}0,5755 \\
\text { s.d } \\
0,8236 \\
\end{array}$ & $\begin{array}{c}0,6827 \\
\text { s.d } \\
0,7165 \\
\end{array}$ \\
\hline $21,3 \mathrm{~cm}$ & 0,6657 & $\begin{array}{c}0,6108 \\
\text { s.d. } \\
0,7204 \\
\end{array}$ & $\begin{array}{c}0,6582 \\
\text { s.d. } \\
0,6731\end{array}$ \\
\hline $22,3 \mathrm{~cm}$ & 0,5781 & $\begin{array}{c}0,4897 \\
\text { s.d. } \\
0,6664\end{array}$ & $\begin{array}{c}0,5660 \\
\text { s.d. } \\
0,5901 \\
\end{array}$ \\
\hline $\begin{array}{l}\text { semua } \\
\mathrm{P}\end{array}$ & 0,6349 & $\begin{array}{c}0,5887 \\
\text { s.d. } \\
0,6811 \\
\end{array}$ & $\begin{array}{c}0,6280 \\
\text { s.d. } \\
0,6418 \\
\end{array}$ \\
\hline
\end{tabular}

Jika Tabel 3 dan Tabel 2 diterjemahkan menjadi gambar maka akan menghasilkan Gambar 15: 


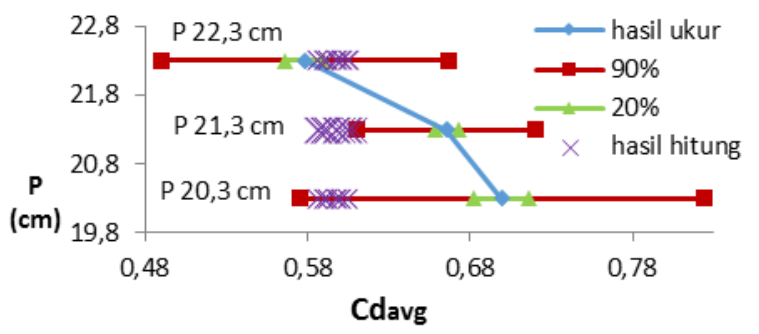

Gambar 14. Nilai $\mathrm{Cd}_{\text {avg }}$ hasil ukur dengan interval kepercayaannya dan $\mathrm{Cd}_{\text {avg }}$ hasil hitung

Dengan interval kepercayaan $90 \%$ pada distribusi Student maka baru sebagian besar $\mathrm{Cd}_{\text {avg }}$ hasil hitung yang akan tercakup dan dengan interval kepercayaan $20 \%$ maka sedikit sekali $\mathrm{Cd}_{\text {avg }}$ hasil yang akan tercakup. Distribusi Student digunakan karena menyerupai distribusi normal, selain tidak memerlukan variansi yang sulit ditentukan besarnya pada diagram $\mathrm{Q} / \mathrm{K}$ terhadap $\mathrm{H}^{2,5}$.

Analisis antara $\mathrm{Cd}$ terhadap $\mathrm{Q}, \mathrm{H}, \mathrm{Q}^{-1}, \mathrm{H}^{-1}$, $\mathrm{Q} / \mathrm{K}, \quad \mathrm{K} / \mathrm{Q}, \quad \mathrm{H}^{2,5}$, maupun $\mathrm{H}^{2,5}$ belum dapat menjelaskan pengaruh $\mathrm{P}$ terhadap $\mathrm{Cd}$ karena dapat terjadi perpotongan antara kurva yang dihasilkan persamaan-persamaan hasil regresi. Hal yang sama juga terjadi dengan analisis regresi antara logaritma Cd terhadap logaritma $\mathrm{Q}$, logaritma $\mathrm{H}$, logaritma $\mathrm{Q} / \mathrm{K}$, maupun logaritma $\mathrm{H}^{2,5}$.

Selisih yang besar antara $\mathrm{H}, \mathrm{Q}, \mathrm{Cd}_{\text {avg }}$, dan $\mathrm{Cd}$ hasil ukur terhadap hasil hitungnya disebabkan beberapa hal antara lain karena turbulensi pada aliran (menyebabkan kesalahan dalam membaca mistar), wadah penampung yang kecil untuk $Q$ yang besar, dan kesalahan paralaks dalam membaca mistar. Jika penelitian kembali dilakukan, maka sebaiknya digunakan weirmeter yang lebih panjang agar efek turbulensi mengecil, wadah penampung yang lebih besar agar tidak kesulitan mengukur Q yang besar atau menggunakan flowmeter, dan weirmeter yang terbuat dari akrilik agar menghindari kesalahan paralaks.

\section{SIMPULAN}

Berdasarkan pengolahan dan analisis data yang telah dilakukan maka untuk menjawab tujuan penelitian dapat disimpulkan:

1. Koefisien discharge yang didapat dari weirmeter dengan panjang $200 \mathrm{~cm}$ dan lebar $35,5 \mathrm{~cm}$ dengan weir sharp-crested $v$-notch $90^{\circ}$ adalah:
a. 0,6996 jika tinggi weir $20,3 \mathrm{~cm}$
b. 0,6657 jika tinggi weir $21,3 \mathrm{~cm}$
c. 0,5781 jika tinggi weir $22,3 \mathrm{~cm}$

2. Pola antara koefisien discharge dengan ketinggian weir yang didapatkan adalah ketinggian weir berbanding terbalik dengan koefisien discharge. Koefisien discharge berbanding lurus dengan debit.

3. Koefisien discharge yang didapat belum sesuai koefisien discharge rata- rata dari literatur karena diperlukan interval kepercayaan sangat besar (90\%) agar koefisien discharge menurut literatur tercakup dalam distribusi Student (distribusi t). Koefisien discharge ratarata dari literatur adalah 0,578.

Dari pengukuran dan perhitungan dapat disimpulkan bahwa

1. Besarnya q konduksi pada cover lama adalah $101,12 \mathrm{~W} / \mathrm{m}^{2}$ dan pada cover baru adalah $82,87 \mathrm{~W} / \mathrm{m}^{2}$.

2. Besarnya $\Sigma$ Rth pada cover lama adalah $0,0386 \mathrm{~K} \mathrm{~m}^{2} / \mathrm{W}$ dan pada cover baru adalah $0,2886 \mathrm{~K} \mathrm{~m}^{2} / \mathrm{W}$.

3. Besarnya laju perpindahan panas menyeluruh pada cover lama adalah $66,18 \mathrm{~W} / \mathrm{m}^{2}$ dan pada cover baru adalah $57,1 \mathrm{~W} / \mathrm{m}^{2}$.

\section{SARAN}

Jika penelitian dilanjutkan, maka sebaiknya digunakan weirmeter yang lebih panjang agar efek turbulensi mengecil, menggunakan flowmeter, weirmeter yang terbuat dari akrilik agar menghindari kesalahan paralaks, lebih banyak variasi ketinggian weir dan interval antar variasinya juga lebih besar.

\section{DAFTAR PUSTAKA}

Chow, V. T. (1959). Open-channel hydraulics. In Open-channel hydraulics. McGraw-Hill.

Michael, A. M. (1978). Irrigation Theory and Practice, Vikas Publishng House Pvt. Ltd. India.

Shen, J. (1981). Discharge characteristics of triangular-notch thin-plate weirs (No. 1617). United States Department of the Interior, Geological Survey.

Munson, B. R., Young, D. F., \& Okiishi, T. H. (2006). Fundamentals of Fluid Mechanics, John Wiley \& Sons. Inc., USA.

Moran, M. J., Shapiro, H. N., Boettner, D. D., \& Bailey, M. B. (2010). Fundamentals of engineering thermodynamics. John Wiley \& Sons.

Fox, R. W., McDonald, A. T., \& Pritchard, P. J. (2010). Introduction to fluid mechanics. 5th.

Elger, D. F., Williams, B. C., Crowe, C. T., \& Roberson, J. A. (2013). Engineering fluid mechanics. Energy, 2, 03-01.

Çengel, Y. A., \& Boles, M. A. (2008). Thermodynamics: an engineering approach, $-P D F$. McGraw-Hill.

Bijankhan, M., \& Ferro, V. (2017). Dimensional analysis and stage-discharge relationship for 
weirs: a review. Journal of Agricultural Engineering, 48(1), 1-11.

Pandey, R., Mittal, S. K., \& Choudhary, M. K. (2016). Flow characteristics of sharp crested rectangular weir: a review. Int. J. Innov. Sci., Eng. Technol, 3, 171-178.

Arvanaghi, H., \& Oskuei, N. N. (2013). Sharpcrested weir discharge coefficient. Journal of Civil Engineering and Urbanism, 3(3), 87-91. 